\title{
An Empirical Study on the Resilience and Organizational Commitment of Childcare Teachers Facing Job Stress
}

\author{
Yeon $\mathrm{Kim}^{1}$, Mi-Na Lee ${ }^{2}$ \\ ${ }^{I}$ The Doctor's Course, Department of Human Service Education, Kwangshin University, South Korea, \\ skyaahjaa@daum.net \\ ${ }^{2}$ Professor, Welfare Counseling Convergence Department, Kwangshin University, South Korea, \\ lmn4780@naver.com
}

Corresponding author: Mi-Na Lee

\begin{abstract}
This study was conducted to investigate the experiences of childcare teachers on resilience and organizational commitment according to job stress. For high-quality childcare and holistic development of a child, not only physical resources but also competent human resources, childcare teachers are important. Nursery teacher is a job engaged in childcare for the development and growth of infants and young children, and it requires a heart to serve and love to sacrifice for young children. This study was conducted to examine the effectiveness of childcare teachers based on their resilience and organizational commitment while being faced with job stress. The participants of this study are six childcare teachers working in a daycare center. The results revealed that, childcare teachers experienced stress in their relationship with infants and young children, especially due to problematic behavior, difficulties in controlling, the burden of childcare services tailored to individual characteristics, and misunderstandings or conflicts that arise when parents distrust teachers. It was found that they had a hard time with the lack of social support and low human rights awareness. Therefore, it can be seen that stress management is very important for childcare teachers who play an important role in the positive emotional experience and sound growth and development of infancy and early childhood.
\end{abstract}

Keywords: Childcare Teacher, Job Stress, Resilience, Organizational Commitment, Experience Research

\section{Introduction}

Women's social advancement and economic activities is important than ever in today's rapidly changing society. As working women and working mothers have become important, interest in daycare centers and the importance of childcare are growing. The rate of use of childcare facilities is increasing, and hence more and more diverse forms of childcare services.

For this reason, the government is interested in quality childcare services and is expanding various national policy projects to provide a better childcare environment. Since 1995, quantitative growth has been achieved by steadily expanding childcare facilities, and various prior studies have been published by the government and the academic association calling for the improvement of the quality level of childcare[1]. Among the many factors that determine the quality of child care, the most important is childcare teachers, and in order to improve the quality of child care, it is essential to understand the development of infants and to have professional childcare teachers who can directly affect infants[2].

Received: August 29, 2021; 1st Review Result: October 14, 2021; 2nd Review Result: November 29, 2021 Accepted: December 31, 2021 
There is growing interest in the importance of various roles of nursery teachers. Among the various roles, the importance of traditional roles, especially for day care teachers, is consistently presented. Playing a role in the image of a child care teacher that most people think is creating far more job stress. The nature of the job to provide services to infants and children without complete communication requires a great deal of responsibility for infant safety, while social awareness and relatively low remuneration often lead to a sense of duty rather than pride in the job. If childcare teachers fail to properly address stress, various forms of maladjustment will inevitably occur. Among the various incidents that occur due to the maladaptation of child care teachers, particularly child abuse, is something that leaves our children, or those involved in child care teachers, with their parents that cannot be washed away.

Recently, parents have been upset as child abuse cases occur at day care center. Amid controversy over some child care teachers' verbal abuse or assault, it is pointed out that childcare institutions, which should be able to entrust children with confidence, have become places to worry about violence.

It is pointed out that poor working conditions of domestic childcare teachers also cause child abuse. According to the Ministry of Health and Welfare's infant care project regulations, one child care teacher in Korea is currently required to take care of three children aged 0 , five children aged 1, seven children aged 2, and fifteen to twenty children aged 4.5. Cite the source of the information presented in paragraphs 4 and 5. In particular, cite the source of the information related to OECD. Critics point out that since the number of children that one teacher has to pay is large, he has no choice but to suffer from work and stress.

In fact, according to last year's "Childcare Center-Kindergarten Teachers' Perception and Demand for Child Rights and Child Abuse," childcare teachers cited the main cause of child abuse as stress. According to a survey of 524 kindergarten teachers at daycare centers in the report, 46.2 percent of teachers said the cause of child abuse was due to "work stress," followed by "teacher's limit of emotion control" with 29.8 percent. Asian economy 2020 as one of the references in the References section and properly cite it in paragraph 6

Child care teachers who are competent human resources as well as physical facilities are important[3] for quality child care for the whole development of infants and children. Spending time with children with appropriate, positive, and consistent interactions are necessary for the their development. Child care teachers will also serve as surrogates to protect and supervise the language, sensory development, health care, nutrition and basic lifestyle, defecation of infants and children. In many ways, day care teachers perform their duties in a different environment from ordinary teachers, which inevitably leads to more stressful situations[4]. In addition, various activities contribute to their stress including interpersonal relationships in daycare centers such as parents and fellow teachers' heads, teaching materials development and class preparation tasks, working environment, learning preparation, administrative work, and participation in education conducted in the floor and outside[5]. Furthermore, child care teachers are stressed by frequent contact with fellow teachers and parents and low wages in addition to physical and mental labor while taking care of the children. The average stress level experience by Korean adults scored, 54.1 points for men and 54.2 for women, while 54.17 points for men and 60.32 for women are found to be under higher-than-average stress[6]. The positive support of child care teachers is a very important part of the stress management of child care teachers because they play an important role in the healthy emotional experience of infants and the growth development of infants.

There are many factors that affect how child care teachers cope with stress. In this study, the researchers will examine the resilience and organizational immersion of child care teachers and consider ways to improve the quality of child care services through experience studies. 


\section{Theoretical Background}

\subsection{Meaning of Daycare Teacher}

According to Article 2(5) of the Infant Care Act, a child care teacher means an expert in charge of child care, health care, counseling with caregivers, and the management and operation of child care facilities. The Ministry of Health and Welfare should also have national certificates for childcare teachers (first, second, and third classes) to help infants achieve their individual abilities with balanced development and growth in the physical, social, emotional, cognitive and linguistic areas of infants. And A nursery teacher is defined as another parenting, emphasizing that the teacher spends a lot of time with infants, not just teaching infants[7][8].

Child care teachers are those who graduate from a department related to early childhood education holding first, second, and third-class child care teacher certificates through child care education and who serve supplementary roles for infants and children in public and private daycare centers. Child care teachers are experts in protection and education in the natural process of infant growth and development, researching and applying educational methods to balance physical, social, emotional and intellectual development, and teaching within the infant environment. Another aspect refers to people who play various roles such as smooth communication with their children so that working parents can do social activities without worrying about their children[9][10]. According to child care statistics (2019), a total of 239,996. The qualification standards for childcare teachers are classified into grades 1,2, and 3, and must be a graduate or have higher education than a high school graduate after completing a certain number of childcare-related subjects and credits from a vocational college or four-year university. In addition, after completing the curriculum set by the Ministry of Health and Welfare's decree and the 240 hours of childcare practice at daycare centers, they will be able to obtain education teacher qualifications(Source: Ministry of Health and Welfare, Infant Care Act, Article 23, Article 20 (4) of the Enforcement Rules of Infant Care Act).

\subsection{Job Stress of Child Care Teachers}

Child care teachers provide childcare services for infants and children with various needs, as well as professional education in various human relationships. In addition, a variety of stressors and symptoms occur in various situations because other workers, such as principals, parents, and fellow teachers, are required to work collaboratively. Under these circumstances, child care teachers must deal with infantrelated tasks quickly, accurately and safely, and in unexpected safety accidents, the weight of quantitative and qualitative roles in addition to child care is more psychologically high than that of ordinary companies[10]. It is true that child care teachers' job stressors are stressful in many ways, unlike other jobs, because they play a significant role in protection and education, connection and effectiveness of infant play and education programs, lack of resources to prepare for work and childcare or events. According to the 2015 survey on child care status, childcare teachers had an average daily working hours (including childcare work, lunch, and break time) of 9 hours and 36 minutes, which is longer than the legal working hours of 8 hours. The childcare teacher said that he/she will perform the roles of constant interaction with infants, preparation and progression of evaluation system for the establishment and systematic management of childcare processes, administrative and facility management, and various affairs and choreography[11].

These job stressors are as diverse as many complicated situations in which child care teachers are exposed, and in addition to child care, stressors include the pressure and role ambiguity of administrative and office work, conflicts with the director, fellow teachers and parents, and concerns that the longer working hours, the lower the quality of child care. Therefore, the job stress management of child care 
teachers is essential, and it is very important to help and pay attention to how child care teachers deal with their stress.

A prior study on job stress for childcare teachers is as follows.

In a study on job stress and job satisfaction of day care teachers, six areas are identified: administrative support factors, treatment factors, peer teacher factors, parent factors, work, factors and work hours factors[12]. In addition, job stress was measured due to administrative support and activities with students, relationships with fellow teachers, economic stability, and overwork, and job stress was measured due to administrative support professors and learning activities, economic stability, task, and parents[13].

Prolonged exposure to job stress by day care teachers resulted in reduced interaction with infants, less tolerance for infant misbehavior, stingy praise, and limited application of creative teaching methods[14][15]. This, in turn, has a negative impact on infants and toddlers at a time of developmental importance[16]. Infant teachers should listen to, record, and determine what to do with infants' interests, goals, sounds, plans and abilities[17].

It was also said that job stress lowers the quality of child care and hinders effective education[18]. Job stress for infant teachers is an important factor that needs to be improved more effectively than anything else because it causes many problems not only for individuals, such as depression and loss of self-esteem, but also social problems such as child abuse. In fact, infant teachers are in charge of various tasks in addition to childcare and education for infants. In addition to childcare and education, other tasks to be performed may lead to neglect of infants or exposure to accidents. These events immediately lead to job stress, and job stress directly affects teachers and infants. The lower the age of a teacher, the higher the stress of a child care teacher[19]. This can be attributed to the lack of experience and expertise in infant care, and the results show that the professionalism of child care teachers and job stress can change depending on their experience. It is said that the job stress felt by day care teachers is the highest in terms of work-related factors because the infant teacher's fatigue continued to accumulate due to more than 10 hours of work and this cumulative work was a stress factor[20].

\subsection{Meaning of Resilience}

Resilience is a term translated into, elasticity, and in Korean, it means the nature of objects transformed by external forces to return to their original state (scientific terminology dictionary, 2014). However, while applying these properties in many fields such as psychology, sociology, psychiatry, biology, psychology is used as a human ability to overcome the serious challenges and difficulties of life and adapt successfully to the environment.

The history of resilience began with an interest in children who grew up in families with schizophrenia as their mothers. They analyzed the power of children, who showed positive growth despite being in a dangerous situation, and the concept that emerged in this study was resilience. In early studies, resilience has focused on children at risk in medical and environmental situations, but approximately two decades later, the definition of resilience is still unclear[21].

In terms of academic definition, Anthony(1987)[22] defined resilience as the ability to overcome difficulties and grow mentally by adapting to the environment, while Polk(1997)[23] defined it as the ability to transform adversity into an experience of growth, and to turn adversity into an experience of growth.

Leipold and Greve (2009)[24] said that individuals are the result of fairy tales and regulations seen in negative situations.

This definition of resilience varies widely among scholars, but the meaning of the ability to overcome and adapt to the environment is the same[25]. Studies of kindergarten teachers show that highly resilient teachers are resilient in adversity and conflict situations and can overcome difficulties flexibly and 
positively in the same stress situation[21]. Therefore, resilience is a meaningful personal psychological factor in overcoming job stress caused by performing various roles and feeling rewarded for the job.

A prior study on the resilience of recovery experienced by child care teachers is as follows.

The first study of social demographic background variables according to age, marriage, career, and institutional type of child care teacher showed no statistically significant difference in psychological exhaustion and resilience, but in the relevant sub-region, teachers in their 40 s recovered negative emotions through age control, and various experiences. There was a statistically significant difference in the resilience of child care teachers with or without marriage. Unmarried teachers showed lower resilience than married teachers, which can be interpreted as receiving psychological stability from families compared to single teachers[14].

There was no statistically significant difference in resilience based on child care teachers' careers. Teachers with more than four years and less than six years of experience have been shown to have higher personality than teachers with more than seven years and less than nine years of experience[26]. A significant result was found in the resilience of the type of work institution for day care teachers, which showed less difference in the resilience of day care teachers by type of institution compared to individual variations in age and marriage[27].

Secondly, we would like to examine research on psychological background variables on psychological exhaustion, job stress, social support, and teacher efficacy as childcare teachers. A prior study on resilience and emotional labor said that the higher the internal behavior of emotional labor, the higher the resilience, and the effect of emotional labor on interpersonal job stress changes according to self-regulation ability. Child care teachers with high resilience overcome stress and prevent psychological exhaustion by applying their resilience in difficulties and stress situations that arise when performing their duties. It has also been shown to reduce teachers' job stress, increase job satisfaction and help positive mental health[28]. In a prior study of resilience related to social support, higher social support alleviated the psychological exhaustion of child care teachers, such as happiness, psychological well-being, and positive effects related to their teaching roles, such as teacher effectiveness, professor immersion, role performance, and professional awareness. Therefore, we could see that social support was positive for the psychological factors of child care teachers[2][21][29][30].

Third, through the experience of child care teachers, we would like to look at the quantitative and qualitative studies according to the relationship between parents and colleagues and principals. Recuperative child care teachers can apply high emotional labor to high job stress, which can be more resilient than the resulting effects, and affect the quality of education and teacher-infant interaction. In other words, the high level of resilience that day care teachers have is not only a teacher-infant interaction but also a factor that improves the quality of early childhood education[25]. Child care teachers are also involved in relationships with their parents through infants, whose interactions affect the development of all areas, including emotional development, cognitive development, language development, and physical development. Interactions between teachers and parents have emerged in various forms, away from participation in educational activities or support for educational activities. Some teachers experience high stress in their relationships with their parents. Child care teachers may be stressed or burdened by lack of ability or opportunities to interview depending on their experience when interviewing parents. Teachers also said that they feel difficulty in changing jobs because they cannot receive complaints from their parents or lead to positive consultations in the event of conflicts with their parents and disputes or safety accidents.

Therefore, teachers need to develop communication skills or strategies related to their relationships with parents, and parental management skills[31]. Prior studies on the resilience of child care teachers show that the resilience of child care teachers has high impulse control and empathy, and significant differences between individual and institutional variables. In-depth interviews with a small number of day care teachers identified the scope of personal and family social protection and risk factors affecting 
resilience[21][28].

Child care teachers with high resilience can think in the other person's shoes by utilizing their reflective thinking and empathy skills in the event of difficulties in communication and human relationships. In other words, child care teachers with high resilience are less affected by human relationships or communication, and lead themselves to overcome failures and difficulties in human relationships and become better. In exploring the difficulties and resilience of day care teachers, selfdevelopment, open-mindedness, cooperative relationships with fellow teachers, and social support networks are suggested as strategies to explore and enable the difficulties and resilience of day care teachers[32]. Since resilience does not exert influence simply on personal factors, cooperation of the environmental factors of child care teachers, namely those involved in the duties of child care teachers, should be made. Teachers with high recovery elasticity scores also had high interpersonal scores in daycare centers, and all of their relationships with fellow teachers, principals, and parents are also high. In a similar context, studies looking at resilience and interpersonal ability with fellow teachers revealed a significant correlation between resilience and interpersonal ability of teachers[25]. Peer relationships refer to the extent to which they recognize encouragement and support from colleagues around child care teachers, and include teachers to build close trust based on their interest in and mutual respect for the welfare aspects.

Workers in childcare facilities have a large influence on each other due to the small number of fellow teachers as the size of the working institution is small. Among them, fellow teachers play a role in strengthening emotional control and utilization in overcoming teacher's personal frustration. Therefore, confidence and satisfaction have a positive impact on the teacher's individual role. For teachers who receive practical support from fellow teachers, it is said that their control of the job increases, has a buffering effect in terms of emotional depletion, and can be controlled by their ability[32]. In addition, teachers' gatherings to support each other and to discuss informal interaction opportunities and issues with the territories have a positive impact on teachers' job satisfaction. The emotional support of fellow teachers for child care teachers increases the teacher's sense of achievement and satisfaction, and improves the teacher's immersion and dedication to the organization. In addition, smooth human relationships and emotional support with fellow teachers in childcare institutions provide a driving force for passionate devotion to childcare activities targeting infants and children to teachers. Smooth interaction and communication, based on positive relationships with fellow teachers, can lead to achievement and satisfaction with the job and further contribute to the organization. It is also important to work together with teachers because if they are positive and mutually cooperative, it can have a positive impact on infants and parents to provide quality early childhood education[31][32]. The relationship between teachers and principals in childcare institutions is mostly vertical and official, so it is easy to find stressful situations in teachers' daily lives. If the relationship between the director and the nursery teacher continues to obey based on unilateral orders and controlled instructions, the nursery teacher and the principal can become estranged or distorted, resulting in misunderstandings and conflicts, which naturally lowers the satisfaction of teaching life. In addition, the job satisfaction of childcare teachers will be reduced, resulting in poor job performance and increased stress and turnover. This will eventually have a negative impact on infants and children. However, the director, who provides clear expectations and support encouragement to day care teachers, not only changes and directs teachers' personal skills and professionalism, but also provides a decisive factor in the educational environment. Therefore, it is important to form and maintain a harmonious relationship between day care teachers and principals.

\subsection{Meaning of Organizational Immersion}

Organizational immersion refers to teachers' willingness to exert efforts for the organization by 
identifying the goals and duties of the school or the organization to which they belong, and to remain members of the organization[33]. Many studies have shown that organizational immersion reduces individual negative behavior toward organizations and allows organizational improvement and efficient performance of organizational members with predictable data on the outcome of organizational activities [33]. Organizational immersion generally demonstrates organizational performance and static relationships inadequate to loyalty or departure or turnover to the organization[34]. Organizational immersion also has a static effect on organizational effectiveness, the level at which organizations achieve their goals. In other words, organizational immersion plays a role in reducing workplace exit behavior such as perception, absence, and turnover and improving organizational performance and job satisfaction[34]. Teachers with high organizational immersion are attached to the organization to which they belong and identify with themselves, and by having a residual intention, they can improve the organization's performance and manage it reliably[35]. It also has a static effect on organizational effectiveness in relation to fair distribution of tasks, appropriate support for supervisors or colleagues, and various tasks corresponding to task compensation[36]. On the other hand, infant teachers with low organizational immersion can perform tasks in a state of exhaustion and willingness to change jobs, resulting in a decrease in organizational effectiveness by creating a semi-productive organizational culture[37].

A prior study on organizational immersion is as follows.

In infant care sites, teachers face problems due to poor working conditions such as emotional labor, low social awareness of child care sites, excessive labor, and low wages, and these problems prevent them from immersing themselves in their organization[38]. Factors that reduce the immersion of infants and toddlers include discrepancies between the value of daycare centers and the value of teachers, pregnancy planning, difficulties in parallel with raising children, and longing for various experiences other than childcare. In addition, job stress, low job satisfaction, and high turnover also reduce organizational immersion. On the other hand, attachment to infants is a factor that increases tissue immersion. There is a negative perception of frequent turnover[31]. It was said that teachers' participation and ability building are high, and that they could increase their organization's immersion when social support or self-efficacy are high[33].

Teachers with high organizational immersion are able to find value and meaning in their organizational activities by working for the institution and promoting the institution's goals[36]. The higher the organizational immersion, the higher the attachment to the institution, the higher the sense of belonging, the higher the child care center's common interests, and the greater the value and meaning of the institution[39]. Therefore, it is an important factor in improving the quality of child care services and the provision of ideal child care services for teachers and organizational immersion according to the professional support environment of infant education institutions[40]. The high level of organization immersion of infants and toddlers can significantly reduce their intention to change jobs, thereby improving the quality of infant education[41].

\section{Research Method}

\subsection{Research Participants}

The participants were informed of the purpose of the study and the consent was obtained from the teachers who formed rapport among teachers with more than three years of experience in the corporate daycare center. they are selected as participants in the study. The basic information of the study participants is as shown in [Table 1]. 
[Table 1] Basic Information for Study Participants

\begin{tabular}{cccccccc}
\hline NUM & Teacher & Age & $\begin{array}{c}\text { Child } \\
\text { age }\end{array}$ & Sex & Married/Not married & Working time & Job experience \\
\hline 1 & A teacher & 43 & 1 & Female & Married & full time & 2yrs \\
\hline 2 & B teacher & 29 & 2 & Female & Married & full time & 3 yrs \\
\hline 3 & C teacher & 52 & 2 & Female & Married & full time & 4yrs \\
\hline 4 & D teacher & 42 & 3 & Female & Married & full time & 6 yrs \\
\hline 5 & E teacher & 52 & 1 & Female & Married & full time & $7 \mathrm{yrs}$ \\
\hline 6 & F teacher & 38 & 2 & Female & Married & full time & $16 \mathrm{yrs}$ \\
\hline
\end{tabular}

\subsection{Research Tools}

Interviews are conducted as one of the qualitative research methods to examine the resilience of child care teachers and their experience in organizational immersion under stress. In-depth individual interviews was used because the participants can be conveyed based on what others have experienced and have the advantage of understanding the meaning of the experience and gaining insight into the problem. The composition of the questionnaires in this study used two questions of job stress, four questions of resilience, and two questions of organizational immersion. The questionnaires on job stress are developed by Clark (1980) and constructed by D'Arienzo, Maracco and Krajewski (1982) by referring to the tools of Imjin (2000) that complement teachers' job stress factor questionnaires. The questionnaire for resilience was composed of the Resilience Quantity Test (RQT) questions divided into four main areas: emotional control, optimism, empathy, and self-efficacy, referring to Lee Jae-young's draft and modified tools [2012]. The composition of questionnaires to identify organizational immersion was divided into two areas, emotional immersion and normative immersion, referring to the modifications made by Kang Ji-young (2009) by tools developed by Allen and Mayer (1990). The questionnaire was requested to be reviewed by one professor of early childhood education and one director of a corporate daycare center with more than 20 years of experience as a teacher and director. The contents of the questionnaire are as shown in [Table 2].

[Table 2] Questionnaire Content

\begin{tabular}{|c|c|c|c|}
\hline & & & Question \\
\hline 1 & \multirow[b]{2}{*}{ Job stress } & activities with children & When was I stressful to control my class? \\
\hline 2 & & $\begin{array}{l}\text { Interpersonal } \\
\text { relationship }\end{array}$ & What do I think when parents make unreasonable demands? \\
\hline 3 & \multirow{4}{*}{ Resilient elasticity } & Emotional control & How did I control my feelings in an unfortunate situation? \\
\hline 4 & & Optimism & What do you think are the result of my efforts? \\
\hline 5 & & Empathy ability & In what circumstances does my colleagues get angry at me? \\
\hline 6 & & Self-efficacy & $\begin{array}{l}\text { What do I think is a confident and comfortable task, and what is a } \\
\text { difficult and challenging task? }\end{array}$ \\
\hline 7 & \multirow{2}{*}{$\begin{array}{l}\text { Organizational } \\
\text { immersion }\end{array}$} & Emotional immersion & When did I feel strongly attached to this job? \\
\hline 8 & & Normative immersion & $\begin{array}{c}\text { What do you think of colleagues who move jobs in between semesters } \\
\text { because they have bigger economic benefits? }\end{array}$ \\
\hline
\end{tabular}

\subsection{Ethical Considerations of Research Participants}

It is important to consider ethical considerations because the collection of data from about 4-5 people 
based on the interview and interview data of the research participants is usually centered on verbal expressions that reveal the experiences, thoughts, and emotions of the research participants. Research participants' voluntary and right to discontinue, anonymity and confidentiality were explained, and consent was confirmed for decision-making regarding research participation and recording of the interview.

\section{Research Results}

This study conducted individual in-depth interviews with six child care teachers and analyzed the collected data to find out what resilience and organizational immersion experience mean to child care teachers and how they solve difficulties in their lives and educational institutions.

\subsection{What was the Stress Experience of Day Care Teachers?}

\subsubsection{Activities with Original Children}

Among the various stresses that day care teachers experience, children are uncontrollable when they are stubborn, but teachers with old experience disregards this situation.

The children suddenly started crying for no reason and I wanted to stop crying when my classmates cried together but it was hard to control when I couldn't solve it(Teacher A, 2021.06.25)

It's hard to control when you just refuse to eat or insist on moving during lunch(Teacher B, 2021.06.)

I don't think there's a situation that's hard to control right now even though I didn't think of it before.

\subsubsection{Interpersonal Relationship}

Teachers who responded to the interview when parents made unreasonable demands are thinking about the situation where they think and listen to their parents as much as possible.

When parents make unreasonable demands I think as much as possible from the parents' perspective and from the children's perspective and I think it would be comfortable to listen to their demands as much as I can (Teacher D, 2021.06.15)

I'll try to understand and listen to my parents' unreasonable demands as much as possible but I'm a human being so I think I'll be upset (Teacher C, 2021.06.18).

First of all, listen carefully, think about why your parents do that and think about the basics and manuals again Then when too much is out of the box I think I'll consult the director and other fellow teachers(Teacher E, 2021.06.10.)

\subsection{Experience in Resilience}

\subsubsection{Emotional Control}

When asked about how he controlled his emotions in a situation where he felt unhappy, he said that he had a good time with his family and thought positively about himself.

I don't think I've ever felt unhappy, When I'm upset I try to have a lot of fun with my family and have a lot of time for me(F Teacher, 2021.06.03.)

When something difficult happens I think, 'This is also passing' And I try to live happily and forget about it (Teacher A, 2021.06.25)

I reflect on the unfortunate situation when it suddenly appears to be unfortunate. And I tend to pass it on positively as it's understandable. Still, when it is difficult to control I tell my family that I feel the same way(Teacher B, 2021.06.) 


\subsubsection{Optimism}

When asked what results they think they had as much as they tried, most respondents seem to think positively about the results of their efforts.

If you try, I think it will lead to some positive results one day even if it's not right now(Teacher C, 2021.06.18)

I don't think efforts betray you. (Teacher D, 2021.06.15)

I believe in the word that you reap what you sow. So I always think "I'm as mine as I try" and I think I get a lot of good results by trying(Teacher E, 2021.06.10.)

\subsubsection{Empathy Ability}

When asked what situation my co-worker was angry at there was a response that my co-worker did not get angry at me and talked a lot.

There may have been things that made me angry, but no one was particularly angry with me. Instead there are times when we decided to say that something was a little upsetting and I think it was just to coordinate opinions not to get angry loudly (Teacher F, 2021.06.03).

We don't get angry because teachers often talk about trivial things(Teacher A, 2021.06.25).

We don't get angry among ourselves we talk a lot (Teacher B, 2021.06.06.)

\subsubsection{Self-efficacy}

There are many responses that they are familiar with what they thought was confident and comfortable, and difficult and challenging things are about their personal lives and their interactions with children.

I think comfortable work is familiar work including what I'm doing now. Difficult and challenging tasks are exercises that don't work out well with your mind set I do, but it's not easy(Teacher B, 2021.06.16.)

I feel comfortable growing plants and being alone. And it's hard to plan and take responsibility for difficult things depending on my personality (Teacher C, 2021.06.18)

I'm comfortable with what I'm doing right now and I'm comfortable doing activities with my classmates and having fun There's nothing particularly difficult and challenging and I'll do my best if you let me do anything (Teacher D, 2021.06.15)

\subsection{Experience of Organizational Immersion}

They asked about emotional immersion, economic benefits and turnover, and the older the teacher, the more negative the feeling of emotional immersion and the more negative the middle.

\subsubsection{Emotional Immersion}

When asked when they felt strongly involved in daycare centers, many teachers answered that it was time for work at daycare centers and for collaboration with colleagues.

I felt a strong sense of belonging when things went well because I felt the same way as did in the process (Teacher E, 2021.06.10.)

As a principal, I feel particularly strong when feel that my job is important(F teacher, 2021.06.03)

I feel a sense of belonging just by looking at each other and greeting each other in the morning. When something happens, we notice it quickly and worry about each other feel a sense of belonging(Teacher D, 2021.06.15) 


\subsubsection{Normative Immersion}

When asked what they thought about their colleagues moving jobs in the middle of the semester following economic benefits, older teachers seemed to think negatively than younger ones.

In fact, I can't give you advice because I don't know his economic situation in detail, but I think he'll tell me that I need to think about it a little more because it's the semester(Teacher A, 2021.06.25)

I don't think I'm going to get involved in anything like that (Teacher B, 2021.06.)

I don't think quitting during the semester is a responsible act as an adult for any reason(Teacher E, 2021.06.10.)

Child care teachers who participated in this study said that they experienced a variety of stresses at work, including duties, interpersonal relationships, and emotional and physical stress. Nevertheless, most of them replied with a positive mind about themselves that they could overcome unfortunate things and that they were getting along with their colleagues.

\section{Conclusion}

This study conducted individual in-depth interviews to find out what the resilience and experience in organizational immersion of child care teachers means to them and how they feel and solve the difficulties they face in their lives and in educational institutions. Child care teachers are stressed by the difficulty in controlling children's relationships, the burden of individual child care services, misunderstandings and conflicts caused by parents' distrust of teachers in their relationships, and their lack of social support and low human rights.

Based on these results, it is necessary to find the following ways.

First, the support of child care teachers is needed in daycare centers. Teachers who participated in this study said that support and sympathy from fellow teachers and principals are a big help, and at the same time, a support system that can exchange various opinions and information for solving problems is essential in the process of expressing and sharing the difficulties of child care teachers. Second, institutional support is needed in terms of professionalism and welfare of childcare teachers. Institutional support, such as sabbatical years, paid or unpaid leave, and support for assistive personnel for childcare teachers, is essential. There are currently a variety of training programs, but they are not practical and economically helpful, so it is true that they do not reach child care teachers working on the spot. Recognizing that childcare teachers' rest is an opportunity for recharging and an important time for professionalism, institutional support must be provided. Third, it is necessary to develop and distribute psychological support services in terms of teachers' mental health. Currently, healing programs for childcare teachers are still being guided, but it is difficult to attract various participation because most of these training sessions take place during work or after work. Therefore, the medical service system, which is essential for childcare teachers, should be developed to provide support for infant care while working in a better environment. How can you say that child care teachers are stressed by the difficulty in controlling children's relationships, the burden of individual child care services, and misunderstandings and conflicts caused by parents' distrust of teachers in their relationships, and their lack of social support and low human rights. The positive support of child care teachers is an important result of the healthy emotional experience of infants and their growth development of infants, suggesting that the stress management of child care teachers is very important.

The limitations of this study and suggestions for follow-up studies are as follows. First, there is a limit to generalizing the research results because it was conducted for teachers of daycare centers in a specific area. Therefore, it is necessary to conduct follow-up studies in several regions. Second, there is a limit to the study of only self-report data on stress experiences in relationships with infants and young children in childcare facilities. It is necessary to examine the research participants using more diverse 
measurement tools.

\section{References}

[1] M. S. Kim. A study on the quality of workplace childcare services, Ewha Womans University, Master's Thesis, pp.10$15,(1991)$

[2] S. Y. Cho, Child Care Teacher's Job Satisfaction and Burnout, Korean Journal of Human Ecology, (2005), Vol.14, No.1, pp.69-79, UCI: G704-001335.2005.14.1.017

[3] C. Y. Shon, A study on factors affecting burnout of childcare teachers, Gwangju University, Master's thesis, pp.9-13, (2009)

[4] A. S. Yang, Development of job stress scale for childcare teachers, Chosun University, Master's Thesis, pp.11-15, (2008)

[5] J. M. Kim, The effect of childcare teachers' job stress on psychological exhaustion: Focusing on the mediating effect of self-esteem, Hansei University, Ph.D. thesis, pp.8-14, (2016)

[6] S. H. Lee, ChungNam Report No.237: Chungcheongnam-do Employment and Labor Report, ChungNam Institute, pp.1-13, (2016)

[7] M. Y. Sung, J. K. Kim, J. Y. Seo, M. H. Min, Y. M. Kim, Childcare Teacher Theory, Hakjisa, pp.30-45, (2015)

[8] J. Y. Choi, Y. H. Kim, D. K. Kim, Effects of Workplace Social Support on Turnover Intention of Chilcare Center \& Kindergarten Teachers : The Mediating of Emotional Burnout, and Job Satisfaction, Journal of Early Childhood Education \& Educare Welfare, (2015), Vol.19, No.4, pp.573-593, UCI: G704-002073.2015.19.4.020

[9] S. Y. Shon, The effect of art therapy using mandala on job stress of childcare teachers, Hanyang University, Master's thesis, pp.13-17, (2017)

[10] E. Y. Lee, A study on a group art therapy program for childcare teachers' job stress reduction: Focusing on the mandala technique, Hanyang University, Master's thesis, pp.9-14, (2020)

[11] H. J. Kim, The relationship between emotional labor and burnout of childcare teachers: the effect of teacher choice and motivation and work environment adjustment, Kyung Hee University, Master's thesis, pp.8-13, (2016)

[12] S. J. Lee, A study on the resilience of early childhood teachers, Changwon University, Master's Thesis, pp.10-16, (2014)

[13] J. S. Choi, A study on the job stress and motivation of teachers according to the leadership style of kindergarten principals, Wonkwang University, Master's thesis, pp.12-19, (1991)

[14] H. Y. Shin, Effect of job stress and teacher efficacy on the quality of teacher's behavior in daycare centers, Yonsei University, Master's thesis, pp.8-18, (2005)

[15] E. S. Joo, J. Y. Kim, The Effects of Teachers' Efficacy and Occupational Stress on Creative Attitude among Kindergarten Teachers - Examining the mediating effects of Focusing Manner -, Journal of Future Early Childhood Education, (2014), Vol.21, No.2, pp.1-18, UCI: G704-000819.2014.21.2.008

[16] Y. S. Kang, M. K. Kim, The Relationship between Child-Care Teachers' Job Stress and Belief of Teaching Efficacy, Journal of Korean Child Care and Education, (2011), Vol.7, No.4, pp.325-352, UCI: G704SER000010376.2011.7.4.014

[17] E. H. Kim, The relationship between job stress and social support and self-esteem of kindergarten teachers, Yonsei University, Master's thesis, pp.12-19, (2004)

[18] S. E. Bae, Effect of teacher's happiness, job stress, and teacher efficacy on teacher-infant interaction in nursery school nursery school, Catholic University, Master's thesis, pp.8-14, (2016)

[19] H. Y. Shin, A study on the working environment and job stress of early childhood teachers, Yonsei University, Master's thesis, pp.9-15, (2005) 
[20] M. S. Jang, The effect of job stress of childcare teachers on job satisfaction: Focusing on childcare teachers at a daycare center in Cheongju, Cheongju University, Master's Thesis, pp.10-16, (2007)

[21] S. H. Kwon, A Review of literature on early childhood teachers' resilience, Earyl Childhood Education \& Care, (2015), Vol.10, No.2, pp.31-53, DOI: 10.16978/ecec.2015.10.2.002

[22] E. J. Anthony, Risk, vulnerability, and resilience: An overview, Guilford Press, pp.3-48, (1987)

[23] L. V. Polk, Toward a middle-range theory of resilience, Advances in Nursing Science, (1997), Vol.19, No.3, pp.1-13. DOI: 10.1097/00012272-199703000-00002

[24] B. Leipold, W. Greve, Resilince: A Conceptual Bridge Between Coping and Development, European Psycholgist, (2009), Vol.14, No.1, pp.40-50, DOI: https://doi.org/10.1027/1016-9040.14.1.40

[25] S. H. Kim, The relationship between resilience and job satisfaction of kindergarten teachers, Graduate School of Education, Korea National University of Education, Master's thesis, pp.11-15, (2017)

[26] H. J. Goo, M. Y. Kim, A Study on the Resilience and Burn-out of the Teachers in Public Preschools According to Their Personal Variables, Korean Journal of Early Childhood Special Education, (2016), Vol.16, No.1, pp.135-160, UCI: G704-001667.2016.16.1.006

[27] J. Y. Song, The relationship between the resilience of early childhood teachers and the coaching leadership of the principal, Kookmin University, Master's Thesis, pp.9-13, (2017)

[28] S. J. Lee, A study on job stress and coping measures of integrated daycare teachers, Silla University, Master's Thesis, pp.8-15, (2010)

[29] E. S. Lee, Structural relationships among childcare teachers' self-resilience, job stress, childcare efficacy, childcare commitment, and happiness, Dong-A University, Doctoral thesis, pp.9-14, (2016)

[30] H. I. Hwag, J. H. Tack, S. H. Hong, Impact of Resilience, Teacher Efficacy, and Job Satisfaction on Happiness in Early Childhood Teachers, Early Childhood Education Research \& Review, (2013), Vol.17, No.3, pp.411-432, UCI: G704000814.2013.17.3.020

[31] J. A. Kim, Organizational culture and organizational effectiveness of childcare facilities perceived by childcare workers, Dongduk Women's University, Doctoral thesis, pp.13-16, (2008)

[32] K. H. Ryu, S. Kang, Analysis of Structural Model of Emotional Intelligence, Co-teachers' Cooperative Relationship, Parent-Teacher Cooperative Relationship, and Teacher's Efficacy, Journal of Early Childhood Education \& Educare Welfare, (2015), Vol.19, No.2, pp.203-225, UCI: G704-002073.2015.19.2.001

[33] K. S. Kang, The Relationship among Kindergarten Teacher's Empowerment, Followership, School Organizational Commitment, and School Organizational Effectiveness, The Journal of Korean Teacher Education, (2009), Vol.26, No.2, pp.201-224, DOI: 10.24211/tjkte.2009.26.2.201

[34] H. G. Jung, D. S. Shim, M. J. Kim, The Effects of Leaders' Ethical Leadership on Followers' Job Performance, Organizational Commitment and Organization Citizenship Behaviors: The Mediating Effect of Organization-Based Self-Esteem And the Moderating Effect of Corporate Ethical Values, Korean Journal of Business Administration, (2013), Vol.26, No.4, pp.801-827, UCI: G704-000789.2013.26.4.005

[35] D. Chung, H. J. Moon, A Study on Teacher' Perception of Organizational Communication, Conflict, Commitment in Child Care Center, Journal of the Korean Home Economics Association, (2010), Vol.48, No.10, pp.11-23, DOI: https://doi.org/10.6115/khea.2010.48.10.011

[36] S. H. Kim, Effect of job stress and interpersonal ability on psychological exhaustion of the heads of early childhood care and educational institutions, Chonbuk National University, Master's Thesis, pp.12-14, (2015)

[37] E. H. Park, S. B. Jeon, The Investigation of Risk Factors and Protective Factors that Influence Resilience in Kindergarten Teachers, The Journal of Korean Teacher Education, (2010), Vol.27, No.1, pp.253-275, DOI: 10.24211/tjkte.2010.27.1.253

[38] M. H. Seo, M. H. Lee, M. J. Goo, Analysis of job duties and working environment for childcare facility workers, Ministry of Gender Equality and Family, pp.56-75, (2006) 
[39] Y. J. Kim, K. S. Nam, Y. S. Kang, Analysis of The Main Causes of The Effect of The Job Satisfaction to The System Absorption of The Childcare Teachers, Asia-Pacific Journal of Business Venturing and Entrepreneurship, (2014), Vol.9, No.4, pp.135-144, DOI: 10.16972/apjbve.9.4.201408.135

[40] J. G. Lee, A structural analysis of the relationship among childcare teachers' perceived reward perception, emotional labor, job stress, job burnout, and organizational commitment, Daegu Catholic University, Doctoral thesis, pp.8-18, (2013)

[41] J. Y. Lee, The relationship between resilience, perceived social support, and organizational commitment of teachers in early childhood education institutions, Daegu Catholic University, Doctoral thesis, pp.7-14, (2012). 